\title{
Evaluation for the Anthropocene: Sustainability
}

\section{Sean Curry}

\section{Fellows' Strand plenary}

Evaluation for the Anthropocene: Shaping a sustainability-ready evaluation field 2018 Canadian Evaluation Society Conference

My career has been working with different perspectives of sustainability; firstly in the forest industry. I am a professional forester with training and background in Western natural sciences and 25 years of industrial forestry experience. For the last 6 years, I have been working from a different perspective on resource extraction and resource management. I work for the British Columbia Oil and Gas Commission, which regulates the exploration, development, processing, and distribution of petroleum products by the oil and gas industry in British Columbia. Throughout this 30-plus-year career, I have been involved with stakeholders, First Nations, the public, industry, and as a regulator-right in the middle of the conflict between two worldviews of sustainability and the environment. I am speaking today, not as an industrial forester, nor as a representative of 
the regulator, but in a personal capacity, to provide personal opinions and perspectives and observations of this conflict.

I am going to talk about three connected questions:

- How do we define sustainability?

- What is our perspective or worldview on the environment?

- How do you evaluate sustainability?

\section{How do we define sustainability?}

I am going to describe contrasting worldviews to illustrate two very different perspectives on sustainability. I think everyone is familiar with the Western science worldview of a reductionist, pragmatic approach, focused on scientific hypothesis, proofs supported by bodies of research, that backstop a foundation of resource management policy, laws, and institutions. As an industrial forester, I was focused on resource development where the efforts optimise or maximise the extraction of the resource while minimising impacts to natural systems. This worldview is heavily weighted to sustaining resource extraction and treating other values as secondary objectives.

Contrast that with another perspective, based on a cultural or spiritual focus, recognising the interconnectedness of people, traditional practices, and social structures all woven together by a fabric of resource stewardship. A much more interconnected view, an equal footing between humans, species, and things.

Clearly there is a tension between those two worldviews, these two different concepts of sustainability, which are good bookends to the world where I currently work. A world where provincial, federal, first nations, and other interests compete for ascendancy in decisions over natural resources in a highly contested and evolving landscape.

The Canadian government is a signatory to the United Nations Declaration on the Rights of Indigenous People (UNDRIP) but has 
not ratified it, nor brought it into law. It has however committed to implement the recommendations of the Truth and Reconciliation commissions.

The British Columbia government is developing legislation to implement UNDRIP, and has fully accepted the recommendations from the Truth and Reconciliation Commission of Canada. The British Columbia government also fully supports the 2014 Tsilhqot' in decision by the Supreme Court of Canada recognising the Tsilhquot' in claim to Aboriginal title, overturning two lower court earlier decisions favourable to extraction by the timber companies and based on much narrower definitions of historical use. The 2014 unanimous decision of the Supreme Court has far-reaching implications recognising Aboriginal title as a beneficial interest in the land covered by Aboriginal title and according to Aboriginal title-holders, the right to determine how the land will be managed and used.

The combination of these three commitments is shaking the foundations of resource management in British Columbia. The scale of the change is large, there is a mix of excitement and apprehension; it is a very large challenge to all parties involved; provincial ministries, Crown agencies, and institutions, first nations, industry, and the public. The challenge is to reach agreement among all parties on a definition of sustainability that will enable resource management decisions to be made for the benefit all parties. While there are local successes, large-scale integration of these two perspective and worldviews is in its infancy, British Columbia is breaking new ground-it is a fascinating work environment.

\section{What is our perspective or worldview on the environment?}

One perspective in Western science, a pragmatic perspective, can be characterised as a view that the environment is something to be utilised 
for economic gain, for the benefit of humans, with potential consequences to the environment measured and characterised by Western science and impact assessment guided by our tolerance to risk. Complex resource management decisions require policy to guide decision makers, which can accentuate different definitions of sustainability, and highlight different tolerances to risk and methodologies for estimating it.

Western science, science institutions, and universities are in a position of power, and are embedded into laws and legislation, practices, policies, and guidelines along with an inherent tolerance to risk. The prevailing perspective or worldview on the environment is one of balancing economic gain against environmental risk. And because environmental impacts are on a continuum, direct cause and effect can be very difficult to define.

If your perspective is spiritual / cultural there might be a tendency to view the impacts of resource extraction as a threat to your livelihood, your culture and identity, and an abrogation of your stewardship responsibilities.

With British Columbia developing UNDRIP legislation, and its recognition of the Supreme Court Tsilhquot'in decision and fully accepting the recommendations of the Truth and Reconciliation Commission, both concepts of sustainability are valid. One doesn't trump the other, the trick is to think about how do you integrate the two worldviews. The definition of sustainability becomes some sort of combination. We are moving from a predominantly Western view of sustainability to an integrated approach that's not well defined, challenging, and can have deep effects.

\section{How do you evaluate sustainability?}

There is a process underway in Northeast British Columbia that has been going on for several years to try to bridge these two worldviews. It is a complex situation with government, industry, and most of 
the individual bands signatory to Treaty Eight ${ }^{1}$ that are within the boundaries of British Columbia. The objective is to incorporate the relevant worldviews into a decision-making process to optimise the exercise of treaty rights and resource extraction.

It is a very complicated situation, and while this and other projects are underway to bridge these differences, outstanding questions remain:

- How do we couple human and natural systems?

- What processes do we have that effectively integrate Western science, indigenous knowledge, and the institutions and infrastructure that society is based upon?

The challenge is that we need a system that acknowledges and incorporates both the extraction focus as well as a cultural spiritual focus, to create new models and processes.

\section{The author}

As Vice President Operational Policy \& Environment at British Columbia Oil and Gas Commission Sean Curry operates in high-stakes settings where human and natural systems are intrinsically and always coupled. See https://www.linkedin.com/in/ sean-curry-48b78915/

Email: Sean.Curry@BCOGC.ca

1 Initially signed in 1899 with subsequent adhesions, covering an area of about 84,000,000 ha (larger than France) 